\title{
Preoperative Hypovitaminosis D Can Predict Development of Postoperative Cognitive Dysfunction
}

\author{
Ahmed M Salem ${ }^{1 *}$, Ahmed E Salem², Maha M Hagras ${ }^{3}$, Adel F Al Kholy ${ }^{4}$ \\ ${ }^{1}$ Department of Anesthesiology \& ICU, Benha University, Egypt \\ ${ }^{2}$ Department of Anesthesiology \& ICU, Tanta University, Egypt \\ ${ }^{3}$ Department of Clinical Pathology, Tanta University, Egypt \\ ${ }^{4}$ Department of Medical Biochemistry, Benha University, Egypt \\ Submission: March 19, 2019; Published: April 10, 2019 \\ *Corresponding author: Ahmed M Salem, Department of Anesthesiology \& ICU, Faculty of Medicine, Benha University, Egypt
}

\begin{abstract}
Objectives: Preoperative estimation of serum 250H-vitamin D (250HD) level in patients undergoing surgical procedures extending for $>60$ min under sevoflurane anesthesia and correlate these levels with frequency of postoperative (PO) cognitive dysfunction (POCD).

Patients \& Methods: 254 patients; 127 Kuwaiti (Group A) and 127 Egyptian patients (Group B) were evaluated clinically and gave blood samples for ELISA estimation of serum 250HD. Vitamin D sufficiency status was defined as sufficient ( $\geq 75 \mathrm{nmol} / \mathrm{L})$, insufficient ( $50-75 \mathrm{nmol} / \mathrm{L})$ and deficient $(<50 \mathrm{nmol} / \mathrm{L})$ level. Cognitive function was assessed preoperatively, 48-hr, 1-wk and 2-wk PO using the Digit span (DS) test. Anesthetic was induced using propofol, fentanyl and rocuronium, and was maintained with sevoflurane, fentanyl and rocuronium with continuous non-invasive hemodynamic monitoring. Study outcome included the frequency and severity of hypovitaminosis D (HVD) and POCD in studied patients.
\end{abstract}

Results: Only 31 patients (12.2\%) had sufficient VD level with significant difference in favor of Group B. All surgeries were conducted uneventfully within mean operative time of $154.4 \pm 37 \mathrm{~min}$ and mean blood loss of $415 \pm 158 \mathrm{ml}$. Median preoperative DS score was 6, at 48-hr, 1 -wk and 2-wk PO, 153, 124 and 95 patients, respectively had score of <6. Preoperative serum 250HD level showed negative significant correlation with age and BMI, and positive significant correlation with male gender and duration of education. Median PO score on DS testing showed positive significant correlation with serum 250HD, especially in Kuwaiti patients. Statistical analyses defined preoperative low serum $250 \mathrm{HD}$ as significant specific predictor for POCD.

Conclusion: POCD is a common incident event among patients underwent major surgeries consuming long operative time under sevoflurane anesthesia. Old age, high BMI, duration and severity of surgery are co-factors for POCD. Preoperative HVD has a pronounced effect and correlated with these precipitating factors and could be used as independent significant predictor for POCD.

Keywords: Postoperative cognitive dysfunction; Hypovitaminosis D; Sevoflurane; Major surgery; Digit span test

\section{Introduction}

Postoperative cognitive dysfunction (POCD) is a neurologic dysfunction characterized by impairment of memory function and intellectual ability [1]. POCD is also associated with greatly reduced speech processing after surgery [2] as well as increased use of healthcare resources [1]. POCD may persist for a period ranging from weeks to months and affects patient's quality of life [3].

Increasing evidence links POCD to surgery and anesthesia and is recognized as an important neuropsychological adverse outcome in surgical patients [4]. Diagnosis of POCD requires complicated neuropsychological testing and is often delayed, so possible predictor for early detection or prediction of POCD is essential for its prevention and treatment [5]. Also, increasing evidence defined age as a major risk factor for POCD [2].

Multiple studies tried to evaluate biomarkers for screening patients for an increased risk of POCD; preoperative neuronspecific enolase levels are more suitable for assessment of incidence of POCD [6]. The ratio of $\beta$-amyloid and Tau proteins, biomarkers of Alzheimer's disease, can be used in forecasting the occurrence of POCD, especially in elderly patients [7]. Preoperative salivary cortisol AM/PM ratio was significantly associated with the presence of early POCD [5].

Cognitive dysfunction, especially in geriatrics, was found to be associated with or predisposed to by multiple nutritional 
deficiencies [8] with special regard to deficiency of folic acid [9], vitamin B6 [10], vitamin D [11] and vitamin B12 [12].

Vitamin D (VD) is an important secosteroid hormone in skeletal and non-skeletal systems [13]. After absorption, VD is bound to a binding protein to carry it in blood stream to liver to be hydroxylated into 250HD [14], which in the kidneys it is hydroxylated to 1,25-dihydroxy VD; which is the biologically active form of VD [15]. Vitamin D can produce a number of biological effects in many non-skeletal tissues through binding to its receptors present in these tissues [16].

\section{Hypothesis}

The current study supposed that preoperative hypovitaminosis D (HVD) may induce or aggravate POCD.

\section{Design}

Prospective multi-center observational study

\section{Setting}

Anesthesia and Clinical Pathology Departments in Tanta University Hospital, Egypt and Sabah Al Ahmed Hospital, Kuwait

\section{Objectives}

Preoperative estimation of serum 250H-vitamin D (250HD) level in patients assigned for surgical procedures extending for $>60$ min under sevoflurane anesthesia and correlate these levels with the frequency of development of POCD.

\section{Patients \& Methods}

The current study intended to include $>250$ patients assigned for surgical procedures extending for $>60$ min under sevoflurane anesthesia. Exclusion criteria included duration of surgery for $<60$ min, age $<18$ years, endocrinopathy inducing HVD, orthopedic diseases or surgery, maintenance on VD supplemental therapy, pregnancy and/or lactation, chronic kidney diseases. The study protocol was approved by the Local Ethical Committee and all enrolled patients signed written fully informed consents. Group A included native Kuwaiti and Group B included native Egyptian patients and immigrants were excluded from either group. Preoperative preparation included general examination to determine demographic data, baseline clinical and hemodynamic data and to take blood samples for baseline investigations and ELISA estimation of serum 250 HD by a clinical chemist who is blinded about the hypothesis of the study or its outcome.

\section{Sampling \& investigations}

Venous blood samples $(5 \mathrm{ml})$ were collected from the antecubital vein under complete aseptic conditions at booking time. The obtained sample was kept in a plane container and allowed to clot then serum was separated by centrifugation at $3000 \mathrm{rpm}$ for $10 \mathrm{~min}$. Serum was removed and placed in pyrogenfree Eppendorf tubes and stored at $-70^{\circ} \mathrm{C}$ until ELISA assayed by Spectrophotometer for estimation of 250HD using the Calbiotech Vitamin D Kit (Calbiotec, A Life Science Co, USA; Catalog No.
VD220B) which is a solid phase enzyme-linked immunoassay (ELISA) based on the principal of competitive binding [17].

\section{Clinical evaluation}

a) Vitamin D sufficiency status was defined according to 25 -OHD concentration as follows: $\geq 75 \mathrm{nmol} / \mathrm{L}$ sufficient level, $50-75 \mathrm{nmol} / \mathrm{L}$ insufficient level and $<50 \mathrm{nmol} / \mathrm{L}$ deficient level. Vitamin D deficiency was categorized as mild, moderate and severe if 25-OHD concentration was $25-50 \mathrm{nmol} / \mathrm{L}$, $12.5-25 \mathrm{nmol} / \mathrm{L}$ and $<12.5 \mathrm{nmol} / \mathrm{L}$, respectively [18].

b) Cognitive function was assessed preoperatively, 48hr, 1-wk and 2-wk postoperatively (PO) using the Digit span (DS) test: Forward DS tests are used to measure short-term memory and general attention. Backward DS tests are used to measure verbal working memory [19-21].

\section{Preoperative preparation}

Patients were preoperatively evaluated for ASA grade and presence of associated co-morbidities. Patients with comorbidities were adjusted and were maintained on their preoperative therapies till day of surgery and postoperatively to maintain the control state. Patients were premedicated by midazolam $0.02 \mathrm{mg} / \mathrm{kg}$.

\section{Anesthetic procedure}

Anesthesia was induced, in studied groups, using propofol $2 \mathrm{mg} / \mathrm{kg}$, fentanyl $1-2 \mathrm{ug} / \mathrm{kg}$, and rocuronium $0.6 \mathrm{mg} / \mathrm{kg}$, and was maintained with sevoflurane, fentanyl and rocuronium. After tracheal intubation, the lungs were ventilated with $100 \% \mathrm{O}_{2}$ in air using a semi-closed circle system for a tidal volume of $6-8 \mathrm{ml} /$ $\mathrm{kg}$, and end-tidal carbon dioxide $\left(\mathrm{paCO}_{2}\right)$ of 32-35mmHg. Patients were continuously non-invasively monitored for Mean Arterial Pressure (MAP) and Heart Rate (HR).

\section{Clinical Evaluation}

a) Primary outcome: The frequency and severity of preoperative HVD in patients of both communities

b) Secondary outcome

c) The frequency and severity of POCD in patients of both groups.

d) The relationship between POCD and demographic data, preoperative 25-OHD levels, duration of anesthesia, and the need for ICU admission

e) Intraoperative and PO hemodynamic changes

f) operative and PO complications

g) Frequency of ICU admission and duration of ICU stay

\section{Sample size calculation}

Review of literature showed that the overall incidence of HVD in Middle East ranged from 37.5\% [22] to 26\% [23], to get study 
power of $80 \%$ with $\alpha$ value of 0.05 and $\beta$ value of 0.2 , sample size per group was calculated to be 120 patients.

\section{Statistical analysis}

Obtained data were presented as mean \pm SD, numbers and percentages. Results were analyzed using paired t-test, One-way ANOVA Test and Chi square test. Statistical analysis was conducted using the IBM SPSS (Version 23, 2015) for Windows statistical package. $P$ value $<0.05$ was considered statistically significant.
Results

The study included 284 patients eligible for evaluation, 30 patients were excluded for not fulfilling the inclusion criteria and 254 patients were enrolled; 127 Kuwaiti (Group A) and 127 Egyptian patients (Group B) (Figure 1). Interestingly, mean educational duration was significantly longer and the frequency of employed patients was significantly higher among Egyptian than Kuwaiti patients. Patients collected from both communities showed non-significant $(\mathrm{p}>0.05)$ difference as regards preoperative data (Table 1).

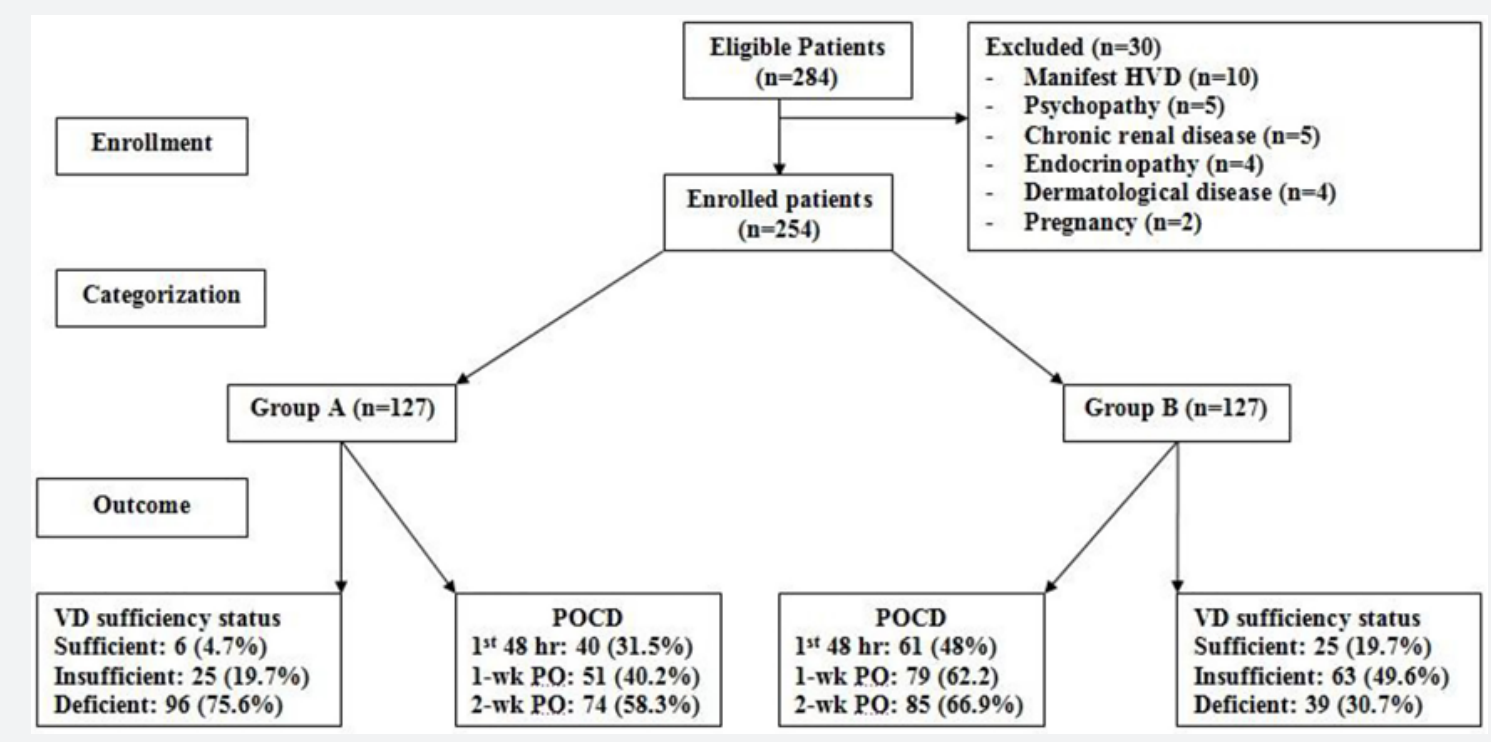

Figure 1: Flow chart of the study.

Table 1: Demographic and preoperative data of studied patients categorized according to patients' community.

\begin{tabular}{|c|c|c|c|c|c|}
\hline & & Total & Group A (Kuwaiti) & Group B (Egyptians) & $P$ value \\
\hline \multicolumn{2}{|c|}{ Age (years) } & $55.9 \pm 16.3$ & $56.3 \pm 16.1$ & $55.5 \pm 16.6$ & 0.587 \\
\hline \multirow{2}{*}{ Gender; M: F } & Males & $113(44.5 \%)$ & $58(46.7 \%)$ & $55(43.3 \%)$ & \multirow{2}{*}{0.705} \\
\hline & Females & $141(55.5 \%)$ & $69(54.3 \%)$ & $72(56.7 \%)$ & \\
\hline \multirow{3}{*}{ BMI data } & Weight (kg) & $84.7 \pm 11.6$ & $83.7 \pm 10.9$ & $85.7 \pm 12.2$ & 0.184 \\
\hline & Height (cm & $169.4 \pm 3.6$ & $169.7 \pm 3.8$ & $169.6 \pm 3.7$ & 0.481 \\
\hline & BMI $\left(\mathrm{kg} / \mathrm{m}^{2}\right)$ & $29.4 \pm 4.1$ & $29.2 \pm 4$ & $29.5 \pm 4.2$ & 0.501 \\
\hline \multirow{4}{*}{ Educational years } & $5-10$ & $91(35.8 \%)$ & $62(48.8 \%)$ & $29(22.8 \%)$ & \multirow{3}{*}{0.0001} \\
\hline & $>10-15$ & $106(41.7 \%)$ & $43(33.9 \%)$ & $63(49.6 \%)$ & \\
\hline & $>15$ & $57(22.5 \%)$ & $22(17.3 \%)$ & $35(27.6 \%)$ & \\
\hline & Total & $11.7 \pm 3.5$ & $10.8 \pm 3.6$ & $12.6 \pm 3.2$ & 0.089 \\
\hline \multirow{2}{*}{ Employment } & Yes & $153(60.2 \%)$ & $69(54.3 \%)$ & $85(66.9 \%)$ & \multirow{2}{*}{0.039} \\
\hline & No & $101(39.8 \%)$ & $58(46.7 \%)$ & $42(33.1 \%)$ & \\
\hline \multirow[t]{3}{*}{ ASA grade } & I & $50(19.7 \%)$ & $24(18.9 \%)$ & $26(20.5 \%)$ & \multirow{3}{*}{0.825} \\
\hline & II & $143(56.3 \%)$ & $70(55.1 \%)$ & 73 (57.5\%) & \\
\hline & III & $61(24 \%)$ & $33(26 \%)$ & $28(22 \%)$ & \\
\hline \multirow{2}{*}{$\begin{array}{l}\text { Ass. Medical co-mor- } \\
\text { bidities }\end{array}$} & No & $69(27.2 \%)$ & $33(26 \%)$ & $36(28.3 \%)$ & \multirow{2}{*}{0.782} \\
\hline & Yes & $185(72.8 \%)$ & $94(74 \%)$ & $91(71.7 \%)$ & \\
\hline
\end{tabular}

Data are presented as numbers and mean $\pm S D$; percentages are in parenthesis; VD: Vitamin $D$; $P$ value indicates the significance of difference between both groups. 
At time of enrolment; 31 patients (12.2\%) had sufficientand 88 patients (34.6\%) had insufficient, while 135 patients (53.2\%) had deficient VD level with significant $(p=0.00001)$ in favor of Group B. Among patients had deficient VD level, 48 patients (35.6\%) had mild, 55 patients $(40.7 \%)$ had moderate and 32 patients $(23.7 \%)$ had severe HVD with significant $(\mathrm{p}=0.0001)$ difference in favor of
Group B. Mean serum VD levels were non-significantly ( $p=0.262)$ higher in patients of group B than those of group A. Despite of the significantly higher level of VD in patients of group B who had insufficient and deficient VD than corresponding patients of group A, patients of group B having sufficient VD had non-significantly $(\mathrm{p}=0.515)$ higher serum VD levels than those of group A (Table 2).

Table 2: At enrolment serum VD status of studied patients categorized according to patient's community

\begin{tabular}{|c|c|c|c|c|c|c|}
\hline Parameters & \multicolumn{2}{|c|}{ Group VD status } & Total & Group A (Kuwaiti) & Group B (Egyptians) & $P$ value \\
\hline \multirow{3}{*}{$\begin{array}{c}\text { Patients' } \\
\text { distribution }\end{array}$} & \multicolumn{2}{|c|}{ Sufficient } & $31(12.2 \%)$ & $6(4.7 \%)$ & 25 (19.7\%) & \multirow{3}{*}{0.00001} \\
\hline & \multicolumn{2}{|c|}{ Insufficient } & $88(34.6 \%)$ & $25(19.7 \%)$ & $63(49.6 \%)$ & \\
\hline & \multicolumn{2}{|c|}{ Deficient } & $135(53.2 \%)$ & $96(75.6 \%)$ & $39(30.7 \%)$ & \\
\hline \multirow{6}{*}{ Level (nmol/L) } & \multicolumn{2}{|c|}{ Sufficient } & $77.7 \pm 2.9$ & $77 \pm 1.5$ & $77.9 \pm 3.2$ & 0.515 \\
\hline & \multicolumn{2}{|c|}{ Insufficient } & $66 \pm 6.4$ & $61.5 \pm 5.6$ & $67.8 \pm 5.9$ & 0.00002 \\
\hline & \multirow{4}{*}{ Deficient } & Mild & $31.8 \pm 3.8$ & $31.9 \pm 3.9$ & $31.8 \pm 1$ & 0.943 \\
\hline & & Moderate & $18.7 \pm 4.1$ & $19.3 \pm 4.1$ & $17.4 \pm 3.9$ & 0.111 \\
\hline & & Severe & $10.9 \pm 0.9$ & $10.7 \pm 1.1$ & $10.9 \pm 0.7$ & 0.545 \\
\hline & & Total & $21.8 \pm 8.9$ & $24.3 \pm 8.6$ & $16.1 \pm 6.8$ & 0.00001 \\
\hline \multicolumn{3}{|c|}{ Total } & $44.1 \pm 24.9$ & $34.4 \pm 19.2$ & $53.9 \pm 26.2$ & 0.00001 \\
\hline
\end{tabular}

Data are presented as numbers, percentages and mean \pm SD; VD: Vitamin D; P value indicates the significance of difference between both groups

All surgeries were conducted uneventfully within a mean operative time of $154.4 \pm 37$; range $70-215$ minutes. Mean intraoperative blood loss was $415 \pm 158 \mathrm{ml}$, but no patient required blood transfusion. HR and MAP measures recorded at end of surgery were significantly lower in patients of group A compared to that recorded at time of induction of anesthesia. In group B, at end of surgery, MAP measures were significantly lower, while HR measures were non-significantly lower than them at-induction measures. MAP measures at end of surgery were non-significantly higher, while HR measures were significantly $(p=0.036)$ higher in patients of group B compared to patients of group A (Figure 1).
Thirty-eight (15\%) patients required transfer to ICU for hemodynamic and respiratory stabilization; 25 patients of group A and 13 patients of group B with significantly ( $p=0.035)$ higher frequency among patients of group A. Mean ICU stay duration was $31.7 \pm 17.8$; range: $12-72 \mathrm{hr}$ with non-significant $(\mathrm{p}=0.302)$ difference between both groups. The remaining patients were transferred to post-anesthetic care unit (PACU) and shifted to surgical ward after a mean duration of $87 \pm 45.8$; range: $30-240 \mathrm{~min}$, with non-significant $(\mathrm{p}=0.363)$ difference between patients of both groups (Table 3).

Table 3: $\mathrm{IO}$ and immediate PO data of studied patients categorized according to patient's community.

\begin{tabular}{|c|c|c|c|c|c|c|}
\hline \multicolumn{3}{|c|}{ Group Parameter } & Total & Group A (Kuwaiti) & Group B (Egyptians) & $P$ value \\
\hline \multicolumn{3}{|c|}{ Operative time (min) } & $154.4 \pm 37$ & $150 \pm 38.8$ & $158.8 \pm 34.6$ & 0.698 \\
\hline \multicolumn{3}{|c|}{ Intraoperative blood loss (ml) } & $415.7 \pm 158.2$ & $421.5 \pm 162.2$ & $409.8 \pm 154.6$ & 0.762 \\
\hline \multirow{4}{*}{$\begin{array}{l}\text { Hemodynamic } \\
\text { changes }\end{array}$} & \multirow{2}{*}{ HR (beats/min) } & Pre & $77.1 \pm 7.9$ & $76.7 \pm 8.9$ & $77.6 \pm 6.8$ & 0.331 \\
\hline & & $\mathrm{PO}$ & $75.3 \pm 6.7$ & $74.1 \pm 6.2^{*}$ & $76.4 \pm 7.1$ & 0.036 \\
\hline & \multirow{2}{*}{ MAP (mmHg) } & Pre & $87.3 \pm 5$ & $86.8 \pm 5.5$ & $87.7 \pm 4.4$ & 0.634 \\
\hline & & PO & $83.3 \pm 10.2$ & $82 \pm 10.7^{*}$ & $84.7 \pm 9.5^{*}$ & 0.102 \\
\hline \multirow{2}{*}{$\begin{array}{c}\text { Immediate PO } \\
\text { care at }\end{array}$} & \multicolumn{2}{|c|}{ ICU } & $38(15 \%)$ & 25 (19.7\%) & $13(10.2 \%)$ & \multirow{2}{*}{0.035} \\
\hline & $\mathrm{PA}$ & & $216(85 \%)$ & $102(80.3 \%)$ & $114(89.8 \%)$ & \\
\hline \multirow{2}{*}{$\begin{array}{l}\text { Duration till shift } \\
\text { to ward }\end{array}$} & \multicolumn{2}{|c|}{ ICU stay (hrs) } & $31.7 \pm 17.8$ & $33.8 \pm 19.4$ & $27.5 \pm 14$ & 0.302 \\
\hline & \multicolumn{2}{|c|}{ PACU stay (min) } & $87 \pm 45.8$ & $90 \pm 45.9$ & $84.2 \pm 46.3$ & 0.363 \\
\hline
\end{tabular}

Data are presented as numbers, percentages and mean \pm SD; IO: Intraoperative; HR: Heart rate; MAP: Mean arterial pressure; PO: Postoperative; ICU: Intensive care unit; PACU: Postanesthetic care unit; P value indicates the significance of difference between both groups; *: indicates significant difference between pre- and PO measures; $p<0.05$ indicates significant difference.

Preoperative median DS score for studied patients was 6; considering this figure as cutoff point; on forward testing, 153 patients $(60.2 \%)$ had score of $<6$ at $48-\mathrm{hr}, 124$ patients $(48.8 \%)$ at 1 -wk and 95 patients (37.4\%) at 2-wk PO and on backward 127 patients $(50 \%)$ had score of $<6$ at 48 -hr, 106 patients $(41.7 \%)$ at 1 -wk and 86 patients (33.9\%) at 2-wk PO. The frequency of 
patients had DS score $<6$ on forward testing was significantly higher in patients of group A than in group B. However, on

backward testing the difference was non-significantly higher between both groups, but in favor of group B (Table 4).

Table 4: PO scores on DS testing of studied patients categorized according to patient's community.

\begin{tabular}{|c|c|c|c|c|c|c|}
\hline Test & Parameter & Time & Total & Group A (Kuwaiti) & Group B (Egyptians) & $P$ value \\
\hline \multirow{7}{*}{ DS Forward testing } & \multirow{3}{*}{$\begin{array}{l}\text { Frequency of DS } \\
\quad \text { score } \geq 6\end{array}$} & 48-hr PO & $101(39.8 \%)$ & $40(31.5 \%)$ & $61(48 \%)$ & 0.007 \\
\hline & & 1-wk PO & $130(51.2 \%)$ & $51(\% 40.2)$ & $79(62.2 \%)$ & 0.0004 \\
\hline & & 2-wk & $159(62.6 \%)$ & $74(58.3 \%)$ & $85(66.9 \%)$ & 0.154 \\
\hline & \multirow{4}{*}{ Score } & Preoperative & $6.9 \pm 0.8$ & $6.9 \pm 0.9$ & $6.8 \pm 0.6$ & 0.218 \\
\hline & & 48-hr PO & $5.5 \pm 1.1^{* *}$ & $5.3 \pm 1^{* *}$ & $5.7 \pm 1.2^{* *}$ & 0.002 \\
\hline & & 1-wk PO & $5.9 \pm 1.4^{* *}$ & $5.5 \pm 1.4^{* *}$ & $6.2 \pm 1.3^{*}$ & 0.00012 \\
\hline & & 2-wk & $6.3 \pm 1.3^{*}$ & $6.2 \pm 1.3$ & $6.4 \pm 1.3$ & 0.191 \\
\hline \multirow{7}{*}{$\begin{array}{l}\text { DS Backward } \\
\text { testing }\end{array}$} & \multirow{3}{*}{$\begin{array}{l}\text { Frequency of DS } \\
\quad \text { score } \geq 6\end{array}$} & 48-hr PO & $127(50 \%)$ & $63(49.6 \%)$ & $64(50.4 \%)$ & 0.902 \\
\hline & & 1-wk PO & $148(58.3 \%)$ & $69(54.3 \%)$ & $79(62.2 \%)$ & 0.203 \\
\hline & & 2-wk & $168(66.1 \%)$ & $83(65.4 \%)$ & $85(66.9 \%)$ & 0.467 \\
\hline & \multirow{4}{*}{ Score } & Preoperative & $7 \pm 1.4^{* *}$ & $7 \pm 1$ & $7.1 \pm 0.7$ & 0.456 \\
\hline & & 48-hr PO & $5.8 \pm 1.1^{* *}$ & $5.7 \pm 1.1^{* *}$ & $5.8 \pm 1.1^{* *}$ & 0.442 \\
\hline & & 1-wk PO & $6.2 \pm 1.4^{*}$ & $5.9 \pm 1.3^{* *}$ & $6.5 \pm 1.5^{*}$ & 0.002 \\
\hline & & 2 -wk & $6.4 \pm 1.5$ & $6.2 \pm 1.5^{*}$ & $6.5 \pm 1.4$ & 0.083 \\
\hline
\end{tabular}

Data are presented as numbers, percentages, mean \pm SD; DS: Digit Span test; P indicates significance of difference between groups A and B; *: indicates significant difference versus preoperative score; *: significance at $<0.05$ level; **: significance at $<0.001$ level.

Mean DS score at 48-hr and 1-wk PO was significantly lower on both forward and backward testing of all patients in comparison to preoperative scores with significantly lower score for patients of group A than group B at 48-hr and 1-wk PO for forward and at 1-wk PO on backward testing. At 2-wk PO, mean DS score was non-significantly lower in patients of group B on forward and backward testing on comparison to preoperative score, while in patients of group A, the difference in score on backward testing was still significantly lower than their preoperative score (Table 4).

Median value of the three PO scores of forward testing was significantly $(Z=3.629, p=0.0003)$ higher in group B (6; IQR: 5-7) than in group A (5; IQR: 5-6) and for backward testing was significantly ( $\mathrm{Z}=3.012, \mathrm{p}=0.003)$ higher in group B (6; IQR: 5-7) than in group A (6; IQR: 5-6). However, for total patients the median value of the three PO scores of forward testing (6; IQR: 5-6) was non-significantly $(\mathrm{Z}=1.679, \mathrm{p}=0.092)$ higher than for backward testing (6; IQR: 5-7).

In total studied population, preoperative serum 250HD level showed negative significant correlation with age and BMI, while showed positive significant correlation with male gender, duration of education. Moreover, median value of estimated PO score on DS testing showed positive significant correlation with preoperative serum 250HD on both forward and backward DS test evaluation. These correlations with preoperative serum 250HD levels were more pronounced in Kuwaiti patients than in Egyptian patients (Table 5).

Table 5: Pearson's correlation coefficient between patients' preoperative data and median value of DS test score, and preoperative serum VD levels.

\begin{tabular}{|c|c|c|c|c|c|c|c|}
\hline \multirow{2}{*}{\multicolumn{2}{|c|}{ Parameter Group }} & \multicolumn{2}{|c|}{ Group A (Kuwaiti) } & \multicolumn{2}{|c|}{ Group B (Egyptians) } & \multicolumn{2}{|c|}{ Total } \\
\hline & & $\mathbf{r}$ & $\mathbf{p}$ & $\mathbf{r}$ & $\mathbf{p}$ & $\mathbf{r}$ & $\mathbf{p}$ \\
\hline \multicolumn{2}{|c|}{ Age } & -0.249 & 0.005 & -0.138 & 0.120 & -0.197 & 0.002 \\
\hline \multicolumn{2}{|c|}{ Male gender } & 0.241 & 0.006 & 0.178 & 0.045 & 0.211 & 0.001 \\
\hline \multicolumn{2}{|c|}{ BMI } & -0.227 & 0.010 & -0.234 & 0.008 & -0.226 & $<0.001$ \\
\hline \multicolumn{2}{|c|}{ Duration of Education } & 0.360 & $<0.001$ & 0.413 & $<0.001$ & 0.388 & $<0.001$ \\
\hline \multicolumn{2}{|c|}{ Employment } & 0.315 & $<0.001$ & 0.252 & 0.004 & 0.284 & $<0.001$ \\
\hline \multirow{2}{*}{ DS testing } & Forward & 0.272 & 0.002 & 0.321 & $<0.001$ & 0.300 & $<0.001$ \\
\hline & Backward & 0.218 & 0.014 & 0.338 & $<0.001$ & 0.285 & $<0.001$ \\
\hline
\end{tabular}

Regression analysis defined preoperative low serum 250HD $p=0.002)$, high BMI $(\beta=0.173, p=0.006)$ and old age $(\beta=0.171$, $(\beta=0.379, \quad p<0.001)$, short duration of education $(\beta=0.203, \quad p=0.007)$ as positive predictors for POCD. ROC curve analysis for 
these predictors defined high BMI as a significant $(\mathrm{p}=0.006)$ sensitive predictor for POCD with AUC=0.371 (95\% CI: 0.283-0.460), while low serum 250HD as significant $(\mathrm{p}=0.006)$ specific predictor with AUC=0.630 (95\% CI: 0.543-0.717) for POCD (Figure 2).

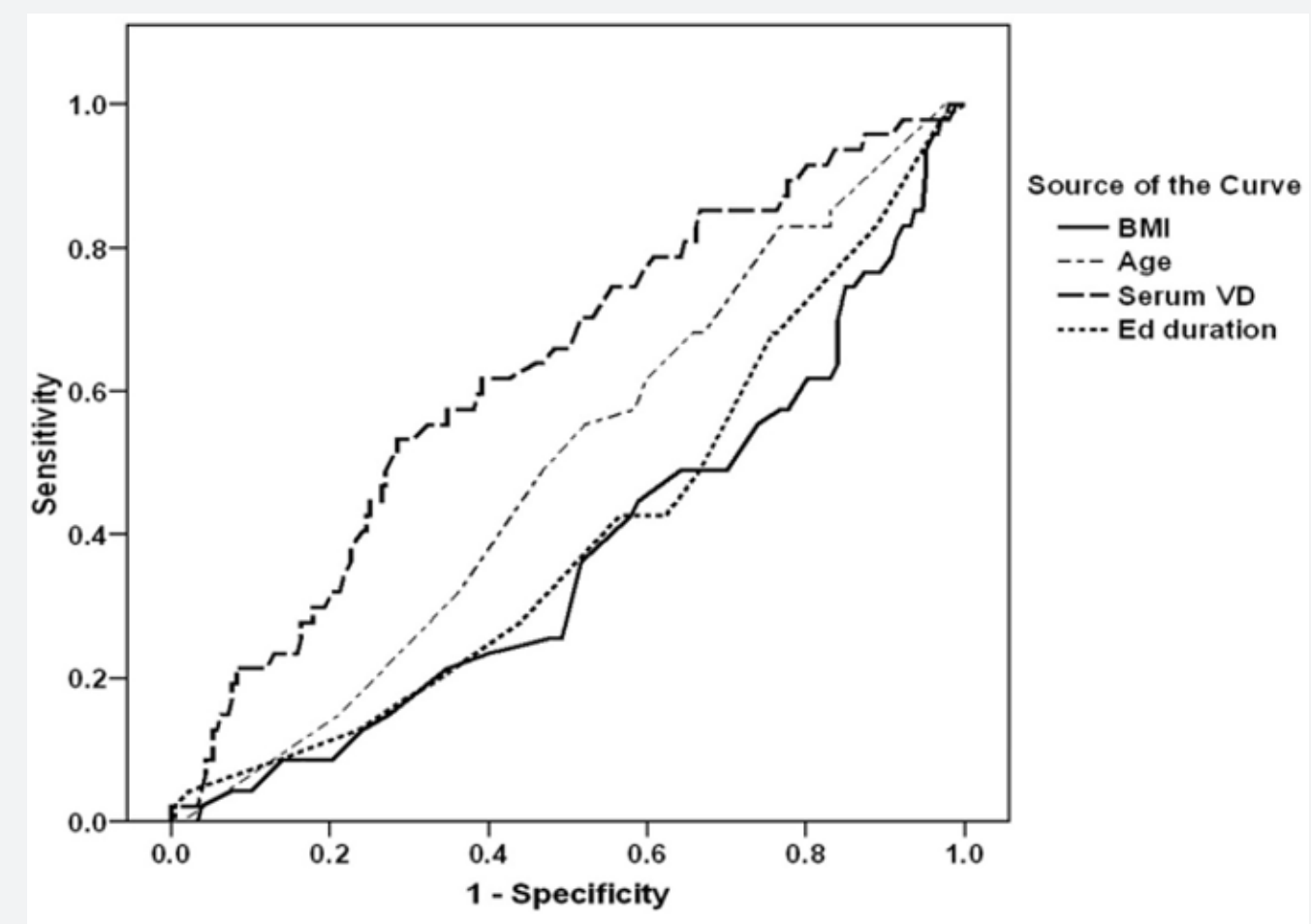

Figure 2: ROC curve analysis for preoperative parameters as predictor for POCD development.

\section{Discussion}

The current study included 254 patients underwent major surgical procedures under sevoflurane anesthesia within a mean operative time of $154.4( \pm 37)$ min and 38 patients had admitted to ICU for a mean duration of $31.7( \pm 17.8) \mathrm{hr}$. All patients showed significantly lower score on DS test in relation to their preoperative score and despite of the progressively regained Cognitive Function (CF), the 2-wk PO scores were still significantly lower than their preoperative scores.

These findings illustrate the deleterious effects of longduration surgery and sevoflurane anesthesia, especially if surgery induced excessive blood loss on CF of patients. However, the underlying etiology and pathogenesis is still a matter of debate, where multiple studies attributed the development of POCD to sevoflurane anesthesia [24-27] secondary to sevoflurane-induced higher levels malondialdehyde [24], TNF- $\alpha$ and IL-6 [26,27] and caspase-3 [27] and/or reduced levels S100B protein [24,26,28]. Other studies reported non-significant difference between frequency and severity of POCD after either of sevoflurane or propofol anesthesia [29-31]. The situation was made worse by Guo et al. [32] who found sevoflurane could improve cerebral oxygenation even in patients with impaired cerebral oxygenation. Moreover, Shoair et al. [25] found using highly anticholinergic or sedative-hypnotic drugs prior to surgery are risk factors for POCD and Sato et al. [33] suggested that the risk of early PO attention dysfunction may be magnified in patients experiencing other risk factors of POCD, as severity of surgery, occurrence of complications, and pre-existing cognitive impairments. Furthermore, Fan et al. [34] found the use of LMA reduced the prevalence of POCD during pediatric neurosurgery than with endotracheal intubation.

The reported continued CD for 2-wk after surgery could be explained depending on the experimental findings of Huang et al. [35] who detected neuro-inflammation, glia activation, aberrant tau phosphorylation and DNA damage in the hippocampus of aged rats underwent a midline laparotomy or exposed to sevoflurane anesthesia alone up to 14 days PO.

About $88 \%$ of studied patients had insufficient-deficient serum 250HD levels, a prevalence which coincided with Chakhtoura et al. [36] who documented that the Middle East and North Africa region is of the lowest serum 250HD concentrations, worldwide. However, HVD was more evident in Kuwaiti than Egyptian patients as manifested by significantly higher frequency of patients had HVD and significantly lower serum 250HD among Kuwaiti patients. These findings spot light on the impact of cultural, environmental and educational factors on VD status. In support of this assumption, the reported significantly higher educational duration and frequency of employee among Egyptian patients and this most probably provided greater opportunity for 
sunlight exposure with subsequent increased VD synthesis. In line with these data and explanation Al-Taiar et al. [37] reported that despite the abundant sunshine in Kuwait, prevalence of VD deficiency and severe deficiency was $81.21 \%$ and $39.48 \%$, respectively and this reflects strong sun avoidance behavior, so adequate outdoor daytime activities should be encouraged.

Preoperative serum VD levels of studied patients showed negative significant correlation with age and BMI, while showed positive significant correlation with male gender, duration of education. Similarly, Golan-Cohen et al. [38] in multivariate analysis of results of cross-sectional study found older age, female gender, higher BMI, sunscreen use, and low sun exposure were associated with lower VD levels and Hashem et al. [39] found most Kuwaiti adolescents are physically inactive and attributed this to low/medium maternal educational levels.

Collectively, median value of PO score on DS test was positively correlated with preoperative serum VD. This finding supported previous reports concerning the association between HVD and poorer mental flexibility [40] or higher likelihood of functional deficits among patients with memory complaint [41], CD in specific domains in old adults [42], and increased problems of memorizing new information [43]. Moreover, these data are consistent with results of VD supplemental intake and slowing, prevention, or improvement of neurocognitive decline [44], decline in verbal fluency [45], or memory loss (46).

Moreover, statistical analyses defined preoperative HVD as positive specific predictor for the possibility for development of POCD. These findings point to a close relationship between VD and cognitive function (CF), so HVD could give an objective predictor for the possibility of development of POCD. Similarly, Sakuma et al. [47] found HVD was independently associated with a higher prevalence of CD and De Oliveira et al. [48] documented that the independent and inverse relation between low 250HD levels and elevated depressive symptoms suggests that HVD may be a risk factor for late-life depression, particularly among women.

Few studies evaluated the relation between HVD and CF disturbances in middle aged populations; the current study included patients in age range of 28-79 years and all these patients showed POCD. Moreover, Similarly, Shu et al. [49] reported that the depth of anesthesia under combined intravenous-inhalational anesthesia yielded milder influence on POCF in young and middleaged patients.

Unfortunately, previous studies dealt with the relation between HVD and POCD were deficient. However, the obtained results go in hand with Zhang et al. [50] who documented that after adjusting for confounding factors, preoperative VD deficiency was associated with an increased risk of POCD. In trial to explore the association between HVD and disturbed $\mathrm{CF}$, Annweiler et al. [51] suggested an association between HVD and dysfunction of the frontal-subcortical neuronal circuits, particularly the dorsolateral circuit in patients with disturbed CF and HVD. Thereafter, Annweiler [51] documented that VD is essential to neurotransmitters and neurotrophins regulation with anti-inflammatory and antioxidant neuroprotective action, so HVD may result in neurological dysfunction that may explain part of the cognitive disorders.

\section{Conclusion}

POCD is a common incident event among patients undergoing major surgical procedures consuming long operative time under sevoflurane anesthesia. Sevoflurane anesthesia could not be accused as the sole precipitating factor. Old age, high BMI, duration and severity of surgery and development of complications are cofactors for upcoming CD. Preoperative HVD has a pronounced effect and correlated with all of these precipitating factors and could be used as an independent significant predictor for POCD.

\section{References}

1. Glumac S, Kardum G, Sodic L, Supe Domic D, Karanovic N (2017) Effects of dexamethasone on early cognitive decline after cardiac surgery: A randomised controlled trial. Eur J Anaesthesiol 34(11): 776-784.

2. Kulason K, Nouchi R, Hoshikawa Y, Noda M, Okada Y, et al. (2017) Indication of Cognitive Change and Associated Risk Factor after Thoracic Surgery in the Elderly: A Pilot Study. Front Aging Neurosci 9: 396.

3. Hayashi K, Oshima H, Shimizu M, Kobayashi K, Matsui S, et al. (2018) Preoperative 6-Minute Walk Distance Is Associated with Postoperative Cognitive Dysfunction. Ann Thorac Surg 106(2): 505-512.

4. Goettel N, Burkhart CS, Rossi A, Cabella BC, Berres M, et al. (2017) Associations Between Impaired Cerebral Blood Flow Autoregulation, Cerebral Oxygenation, and Biomarkers of Brain Injury and Postoperative Cognitive Dysfunction in Elderly Patients After Major Noncardiac Surgery. Anesth Analg 124(3): 934-942.

5. Han Y, Han L, Dong MM, Sun QC, Zhang ZF, et al. (2018) Preoperative Salivary Cortisol AM/PM Ratio Predicts Early Postoperative Cognitive Dysfunction After Noncardiac Surgery in Elderly Patients. Anesth Analg 128(2): 349-357.

6. Cao YH, Chi P, Zhao YX, Dong XC (2017) Effect of bispectral index-guided anesthesia on consumption of anesthetics and early postoperative cognitive dysfunction after liver transplantation: An observational study. Medicine (Baltimore) 96(35): e7966.

7. Wu Z, Zhang M, Zhang Z, Dong W, Wang Q et al. (2018) Ratio of $\beta$-amyloid protein $(A \beta)$ and Tau predicts the postoperative cognitive dysfunction on patients undergoing total hip/knee replacement surgery. Exp Ther Med 15(1): 878-884.

8. Coin A, Veronese N, De Rui M, Mosele M, Bolzetta F, et al. (2012) Nutritional predictors of cognitive impairment severity in demented elderly patients: the key role of BMI. J Nutr Health Aging 16(6): 553556.

9. Malouf M, Grimley EJ, Areosa SA (2003) Folic acid with or without vitamin B12 for cognition and dementia. Cochrane Database Syst Rev 4: CD004514.

10. Malouf R, Grimley Evans J (2003) The effect of vitamin B6 on cognition. Cochrane Database Syst Rev 4: CD004393.

11. Annweiler C, Fantino B, Schott AM, Krolak Salmon P, Allali G, et al. (2012) Vitamin D insufficiency and mild cognitive impairment: crosssectional association. Eur J Neurol 19(7): 1023-1029. 
12. Cho HS, Huang LK, Lee YT, Chan L, Hong CT (2018) Suboptimal Baseline Serum Vitamin B12 Is Associated with Cognitive Decline in People with Alzheimer's Disease Undergoing Cholinesterase Inhibitor Treatment. Front Neurol 9: 325.

13. Yoon HK (2017) Gestational Diabetes Mellitus, Fetal Growth and Vitamin D. J Bone Metab 24(3): 155-159.

14. Lapillonne A (2010) Vitamin D, deficiency during pregnancy may impair maternal and fetal outcomes. Med Hypotheses 74(1): 71-75.

15. Cho GJ, Hong SC, Oh MJ, Kim HJ (2013) Vitamin D deficiency in gestational diabetes mellitus and the role of the placenta. Am J Obstet Gynecol 209(6): 560.

16. Teegarden D, Donkin SS (2009) Vitamin D: emerging new roles in insulin sensitivity. Nutr Res Rev 22(1): 82-92.

17. Park JM, Park CY, Han SN (2015) High fat diet-Induced obesity alters vitamin D metabolizing enzyme expression in mice. Biofactors 41(3): 175-182.

18. Stroud ML, Stilgoe S, Stott VE, Alhabian O, Salman K (2008) Vitamin D - a review. Aust Fam Physician 37(12): 1002-1005

19. Brebion G, David AS, Jones HM, Pilowsky LS (2009) Working memory span and motor and cognitive speed in schizophrenia. Cogn Behav Neurol 22(2): 101-108.

20. Koenigs M, Barbey AK, Postle BR, Grafman J (2009) Superior parietal cortex is critical for the manipulation of information in working memory. J Neurosci 29(47): 14980-14986.

21. Naismith SL, Redoblado Hodge MA, Lewis SJ, Scott EM, et al. (2010) Cognitive training in affective disorders improves memory: a preliminary study using the NEAR approach. J Affect Disord 121(3): 258-262.

22. Eggemoen ÅR, Falk RS, Knutsen KV, Lagerløv P, Sletner L, et al. (2016) Vitamin D deficiency and supplementation in pregnancy in a multiethnic population-based cohort. BMC Pregnancy Childbirth 16: 7.

23. Hilger J, Friedel A, Herr R, Rausch T, Roos F, et al. (2014) A systematic review of vitamin D status in populations worldwide. Br J Nutr 111(1): 23-45.

24. Kalimeris K, Kouni S, Kostopanagiotou G, Nomikos T, Fragopoulou E, et al. (2013) Cognitive function and oxidative stress after carotid endarterectomy: comparison of propofol to sevoflurane anesthesia. J Cardiothorac Vasc Anesth 27(6): 1246-1252.

25. Shoair OA, Grasso Ii MP, Lahaye LA, Daniel R, Biddle CJ, et al. (2015) Incidence and risk factors for postoperative cognitive dysfunction in older adults undergoing major noncardiac surgery: A prospective study. J Anaesthesiol Clin Pharmacol 31(1): 30-36.

26. Qiao Y, Feng H, Zhao T, Yan H, Zhang H, et al. (2015) Postoperative cognitive dysfunction after inhalational anesthesia in elderly patients undergoing major surgery: the influence of anesthetic technique, cerebral injury and systemic inflammation. BMC Anesthesiol 15: 154.

27. Fan CH, Peng B, Zhang FC (2018) The postoperative effect of sevoflurane inhalational anesthesia on cognitive function and inflammatory response of pediatric patients. Eur Rev Med Pharmacol Sci 22(12) 3971-3975.

28. Micha G, Tzimas P, Zalonis I, Kotsis K, Papdopoulos G, et al. (2016) Propofol vs Sevoflurane anaesthesia on postoperative cognitive dysfunction in the elderly. A randomized controlled trial. Acta Anaesthesiol Belg 67(3): 129-137.

29. Tang N, Ou C, Liu Y, Zuo Y, Bai Y (2014) Effect of inhalational anaesthetic on postoperative cognitive dysfunction following radical rectal resection in elderly patients with mild cognitive impairment. J Int Med Res 42(6): 1252-1261.
30. Chen G, Zhou Y, Shi Q, Zhou H (2015) Comparison of early recovery and cognitive function after desflurane and sevoflurane anesthesia in elderly patients: A meta-analysis of randomized controlled trials. J Int Med Res 43(5): 619-628.

31. Egawa J, Inoue S, Nishiwada T, Tojo T, Kimura M, et al. (2016) Effects of anesthetics on early postoperative cognitive outcome and intraoperative cerebral oxygen balance in patients undergoing lung surgery: a randomized clinical trial. Can J Anaesth 63(10): 1161-1169.

32. Guo JY, Fang JY, Xu SR, Wei M, Huang WQ (2016) Effects of propofol versus sevoflurane on cerebral oxygenation and cognitive outcome in patients with impaired cerebral oxygenation. Ther Clin Risk Manag 12: 81-85.

33. Sato C, Sekiguchi A, Kawai M, Kotozaki Y, Nouchi R, et al. (2015) Postoperative Structural Brain Changes and Cognitive Dysfunction in Patients with Breast Cancer. PLoS One 10(11): e0140655.

34. Fan CH, Peng B, Zhang FC (2017) Influence of laryngeal mask airway (LMA) insertion anesthesia on cognitive function after microsurgery in pediatric neurosurgery. Eur Rev Med Pharmacol Sci 21(4 Suppl): $37-42$.

35. Huang C, Chu JM, Liu Y, Chang RC, Wong GT (2018) Varenicline reduces DNA damage, tau mislocalization and post surgical cognitive impairment in aged mice. Neuropharmacology 143: 217-227.

36. Chakhtoura M, Rahme M, Chamoun N, El Hajj Fuleihan G (2018) Vitamin D in the Middle East and North Africa Bone Rep 8: 135-146.

37. Al Taiar A, Rahman A, Al-Sabah R, Shaban L, Al Harbi A (2018) Vitamin D status among adolescents in Kuwait: a cross-sectional study. BM] Open 8(7): e021401.

38. Golan Cohen A, Merzon E, Alhin O, Kitai E, Fogelman Y (2016) Blood levels of vitamin D and health-functional status in asymptomatic individuals: a cross sectional study. J Eval Clin Pract 22(6): 946-951.

39. Hashem R, Rey López JP, Hamer M, McMunn A, Whincup PH, et al. (2018) Physical Activity and Sedentary Behaviors Levels of Kuwaiti Adolescents: The Study of Health and Activity Among Adolescents in Kuwait. J Phys Act Health 15(4): 255-262.

40. Annweiler C, Maby E, Meyerber M, Beauchet O (2008) Hypovitaminosis $\mathrm{D}$ and executive dysfunction in older adults with memory complaint: a memory clinic-based study. Dement Geriatr Cogn Disord 37(5-6): 286293.

41. Chhetri JK, De Souto Barreto P, Soriano G, Gennero I, Cantet C, et al. (2018) Vitamin D, homocysteine and n-3PUFA status according to physical and cognitive functions in older adults with subjective memory complaint: Results from cross-sectional study of the MAPT trial. Exp Gerontol 111: 71-77.

42. Nagel G, Herbolsheimer F, Riepe M, Nikolaus T, Denkinger MD, et al. (2015) Serum Vitamin D Concentrations and Cognitive Function in a Population-Based Study among Older Adults in South Germany. J Alzheimers Dis 45(4): 1119-1126.

43. Annweiler C, Doineau L, Gerigne L, Provendier A, Karras SN, et al. (2018) Vitamin D and Subjective Memory Complaint in CommunityDwelling Older Adults. Curr Alzheimer Res 15(7): 664-670.

44. Annweiler C (2016) Vitamin D in dementia prevention. Ann N Y Acad Sci 1367(1): 57-63.

45. Beydoun MA, Hossain S, Fanelli Kuczmarski MT, Beydoun HA, Canas JA, et al. (2018) Vitamin D Status and Intakes and Their Association With Cognitive Trajectory in a Longitudinal Study of Urban Adults. J Clin Endocrinol Metab 103(4): 1654-1668.

46. Pavlovic A, Abel K, Barlow CE, Farrell SW, Weiner M, et al. (2018) The association between serum vitamin d level and cognitive function in older adults: Cooper Center Longitudinal Study. Prev Med 113: 57-61. 
47. Sakuma M, Kitamura K, Endo N, Ikeuchi T, Yokoseki A, et al. (2018) Low serum 25-hydroxyvitamin D increases cognitive impairment in elderly people. J Bone Miner Metab 37(2): 368-375.

48. De Oliveira C, Hirani V, Biddulph JP (2018) Associations Between Vitamin D Levels and Depressive Symptoms in Later Life: Evidence from the English Longitudinal Study of Ageing (ELSA). J Gerontol a Biol Sci Med Sci 73(10): 1377-1382.

49. Shu AH, Wang Q Chen XB (2015) Effect of different depths of anesthesia on postoperative cognitive function in laparoscopic patients: a randomized clinical trial. Curr Med Res Opin 31(10): 1883-1887.
50. Zhang Y, Shan GJ, Zhang YX, Cao SJ, Zhu SN, et al. (2018) First Study of Perioperative Organ Protection (SPOP1) Investigators: Preoperative vitamin $\mathrm{D}$ deficiency increases the risk of postoperative cognitive dysfunction: a predefined exploratory sub-analysis. Acta Anaesthesiol Scand 62(7): 924-935.

51. Annweiler C (2014) Vitamin D and Alzheimer's disease: from an intriguing idea to a therapeutic option. Biol Aujourdhui 208(1): 89-95.

\section{Your next submission with Juniper Publishers} will reach you the below assets

- Quality Editorial service

- Swift Peer Review

- Reprints availability

- E-prints Service

- Manuscript Podcast for convenient understanding

- Global attainment for your research

- Manuscript accessibility in different formats

( Pdf, E-pub, Full Text, Audio)

- Unceasing customer service

Track the below URL for one-step submission https://juniperpublishers.com/online-submission.php 